\title{
Bacia urbano-regional do petróleo: a zona costeira do Espírito Santo associada ao estado do Rio de Janeiro
}

\section{Claudio Luiz Zanotelli, Ednelson Mariano Dota, Francismar Cunha Ferreira} e Rennan Moraes Rodrigues

\section{(2) OpenEdition}

1 Journals

Edição electrónica

URL: http://journals.openedition.org/espacoeconomia/7877

DOI: 10.4000/espacoeconomia.7877

ISSN: 2317-7837

Editora

Núcleo de Pesquisa Espaço \& Economia

Refêrencia eletrónica

Claudio Luiz Zanotelli, Ednelson Mariano Dota, Francismar Cunha Ferreira e Rennan Moraes

Rodrigues, «Bacia urbano-regional do petróleo: a zona costeira do Espírito Santo associada ao estado do Rio de Janeiro », Espaço e Economia [Online], 15 | 2019, posto online no dia 02 novembro 2019, consultado o 05 novembro 2019. URL : http://journals.openedition.org/espacoeconomia/7877 ; DOI : 10.4000/espacoeconomia.7877

Este documento foi criado de forma automática no dia 5 novembro 2019

(c) NUPEE 


\section{Bacia urbano-regional do petróleo: a zona costeira do Espírito Santo associada ao estado do Rio de Janeiro}

Claudio Luiz Zanotelli, Ednelson Mariano Dota, Francismar Cunha Ferreira e Rennan Moraes Rodrigues

\section{Revista Confins - Revista Franco-Brasileira de Geografia}

\section{Link para a Revista:}

1 https://journals.openedition.org/confins/20869

\section{Link para o artigo:}

2 https://journals.openedition.org/confins/21754

\section{Resumo}

Este artigo parte da hipótese que uma bacia urbano-regional está em constituição entre os estados do Espírito Santo e Rio de Janeiro, mas com foco principal no Espírito Santo. Esta bacia se sobrepõe ou é contígua às bacias sedimentares costeiras dos dois estados (em particular entre a região metropolitana de Vitória e a Região Metropolitana do Rio de Janeiro). Estando em processo de formação, tal bacia tem se densificado na última década em função do acentuado desenvolvimento da exploração e extração do petróleo. Para demonstrar tal hipótese, mapeamos as principais infraestruturas e as empresas presentes na bacia urbano-regional, bem como 
os fluxos migratórios e de deslocamento habitat-trabalho, associados ao petróleo no período de 2000 a 2010 a partir dos microdados do Censo Demográfico Brasileiro.

\section{Introdução}

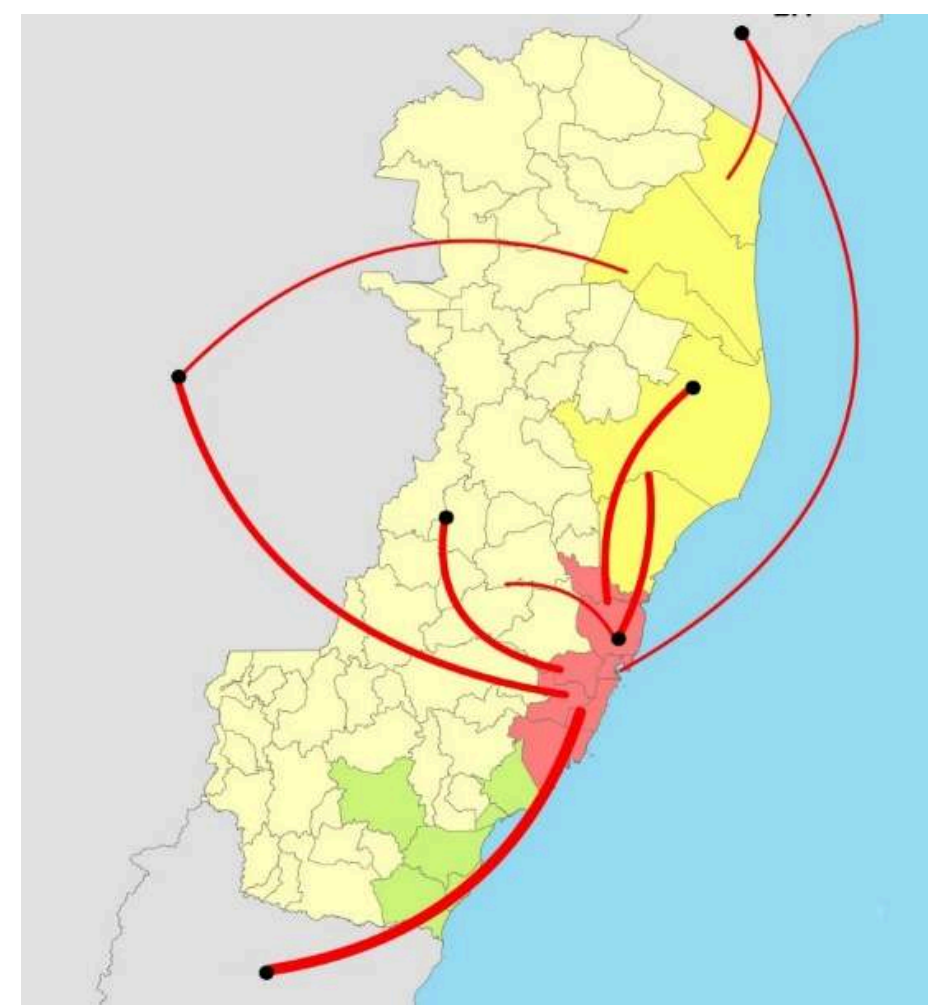

O artigo tem como objetivo principal analisar a migração e os deslocamentos pendulares para trabalho no setor do petróleo, bem como elenca vários elementos infraestruturais e de empresas ligadas ao setor, procurando, assim, revelar um processo interescalar em constituição no espaço urbano e regional, com foco no Espírito Santo em sua conexão ao estado do Rio de Janeiro.

2As zonas costeiras do Espírito Santo e do Rio de Janeiro em seu litoral e na plataforma marítima fazem parte das bacias sedimentares do Espírito Santo, Campos, e Santos onde se encontra grande quantidade de petróleo e gás, principalmente no mar. A bacia de Campos tem aproximadamente $115 \mathrm{mil} \mathrm{km2} \mathrm{e} \mathrm{compreende} \mathrm{parte} \mathrm{do} \mathrm{território} \mathrm{do} \mathrm{norte}$ do Rio de Janeiro e sul do Espírito Santo. A bacia do Espírito Santo possui cerca de 123 mil km2 e compreende a porção centro-norte do território capixaba. A bacia de Santos, por sua vez, se inicia na zona costeira fluminense a partir de Cabo Frio no Rio de Janeiro em direção ao sul e se prolonga até a costa de Santa Catarina e, da mesma forma, tem reservas significativas de petróleo (Cf. Figura 2).

3Desenha-se com a bacia do Espírito Santo e de Campos uma configuração que articula a sobreposição de diversos aspectos territoriais, econômicos, sociais, políticos e ambientais que não se reduzem a uma só escala. Não pretendemos reificar a escala regional e nem dar a ela um estatuto proeminente e dominante. Conforme alerta Neil Brenner (2013 [2009]), os recortes escalares não estão e não são congelados, pois há uma interdependência e uma imbricação mútua e histórica de todas as escalas, quer elas sejam urbanas, regionais, nacionais ou internacionais. Os sistemas de exploração, 
produção e circulação do petróleo, com suas infraestruturas, suas estruturas técnicas e seus fluxos se articulam a complexas relações sociais, ambientais, econômicas e políticas num emaranhado de interescalaridade relacional. Esse processo dinâmico Brenner denomina de escalonamento e de reescalonamento, indicando o processo como heterogêneo, polimórfico, dinâmico das configurações interescalares que não se reduzem a um só aspecto do processo.

7 4É importante sublinhar, nesse sentido complexo, questões de ordem territorial e geopolítica que envolvem um escalonamento em nível internacional em relação aos "territórios do petróleo" (Cf. Monié e Binsztok, 2012), tendo em vista que parte importante da produção se encontra na plataforma continental e principalmente no mar (o pré-sal tendo importância crescente nas reservas e na produção) e praticamente toda ela se encontra para além dos limites das águas territoriais, estes últimos são estabelecidos por tratados internacionais em uma distância de 22,2 km da linha de base do litoral (Cf. IBGE, 2011, p. 29, e o mapa da Figura 2). Portanto, esse território está situado na Zona Econômica Exclusiva (ZEE) reconhecida por tratados internacionais que se define por uma distância, para além do mar territorial, de $348 \mathrm{~km}$ (Idem, IBGE, 2011). A importância marítima da exploração e produção do gás e do petróleo traz consigo também a necessidade de estruturas técnicas e de circulação apropriadas para esse tipo de produção, que demanda bases de apoio em terra via infraestruturas e equipamentos de primeiro plano como portos, aeroportos, empresas de manutenção de plataformas, navios sonda, estaleiros e uma miríade de prestadores de serviços e de produtos os mais diversos (Piquet, 2007).

850 processo de exploração (pesquisas para se encontrar os "recursos") e produção (a extração e transporte propriamente dito) do petróleo traz, por um lado, uma série de impactos sobre o meio ambiente e os aspectos culturais e a organização do trabalho, e, por outro lado, há os impactos nas zonas de apoio à exploração e produção com seus portos e instalações industriais, bem como os efeitos inegáveis sobre as zonas atravessadas por gasodutos e oleodutos.

60s municípios, impactados de maneira direta e indireta pela exploração recebem rendas provenientes de impostos como os royalties e a participação especial. Muitos municípios que, apesar de não se inserirem nessa situação, são confrontantes das áreas de produção no mar bem distante da costa, também participam de maneira considerável da distribuição dessa renda, o que gera um impacto de outra ordem, que é a inversão das rendas milionárias em municípios destituídos de infraestrutura, criando, desse modo, uma dependência da renda e uma distorção na distribuição da remuneração (ver a propósito dessas questões Oliveira, Terra e Givisiez, 2012).

70 volume de reservas e o volume produtivo do setor demonstram a importância das bacias sedimentares marítimas, em particular nos territórios do Rio de Janeiro, do Espírito Santo e de São Paulo. Uma de nossas hipóteses é a de que essas bacias sedimentares - com a análise centrada nesse artigo no Espírito Santo e de maneira complementar no Rio de Janeiro - estão na base do desenvolvimento de uma bacia sócio-econômica que interage de maneira significativa com os fluxos de produtos e os processos relativos ao tipo de emprego, à migração e aos deslocamentos pendulares (habitat-trabalho). Assim, os impactos territoriais provocados pelo petróleo estariam conformando uma "bacia urbano-regional" entre os dois estados e ao mesmo tempo possibilitando a expansão e a conformação do processo de metropolização do espaço por meio dos diferentes e intensos fluxos desenvolvidos no interior dessa bacia. Isso 
será evidenciado pelo mapeamento das principais infraestruturas, das sedes e filiais das empresas do setor presentes ao mesmo tempo no Espírito Santo e no Rio de Janeiro e, principalmente, pela análise dos microdados do Censo Demográfico brasileiro de $2000 \mathrm{e}$ 2010 do IBGE, identificando e analisando o número de trabalhadores do setor petróleo, os fluxos migratórios e de deslocamento pendular (habitat-trabalho) intermunicipal no Espírito Santo e inter-estaduais entre o Espírito Santo e o Rio de Janeiro, o que configura uma divisão territorial do trabalho com especializações territoriais no setor do petróleo.

11 8Para análise dos fluxos migratórios e produtivos apresentados, sobretudo do fluxo de pessoas que se deslocam para trabalhar, lançou-se mão dos dados do Censo Demográfico brasileiro. Inicialmente, cabe destacar que o Censo é a única pesquisa em nível nacional que oferece dados de migração e mobilidade pendular desagregado por município, permitindo a localização da origem (município de residência) e do destino (município de trabalho) do movimento, além do cruzamento com outras informações sociodemográficas dos indivíduos, inclusive permitindo selecionar as pessoas ocupadas no setor de interesse. Uma das limitações desta fonte de dados se refere à periodicidade decenal, o que significa alguma defasagem temporal quanto mais longe está a análise em relação ao período de referência da pesquisa.

9Tal limitação, entretanto, deve ser relativizada, tendo em vista que a limitação do período é compensada pelo detalhamento oferecido pela pesquisa, além da abrangência nacional. Outras pesquisas com periodicidade anual, que permitiriam vencer a limitação temporal, como a PNAD (Pesquisa nacional por amostra de domicílio), do IBGE, ou a RAIS (Relação anual de informações sociais), do Ministério do Trabalho e Emprego (atual Secretaria do Trabalho, do Ministério da Economia), são pesquisas que, pelos objetivos e metodologia de captação dos dados não oferecem o nível de detalhamento necessário para os objetivos aqui elencados (ver Dota; Rodrigues; Barros, Ferreira, 2018). 